\title{
Real-time drought forecasting system for irrigation management
}

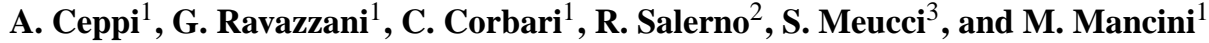 \\ ${ }^{1}$ Department of Civil and Environmental Engineering (D.I.C.A.), Politecnico di Milano, Milan, Italy \\ ${ }^{2}$ Epson Meteo Centre, Cinisello Balsamo (Milan), Italy \\ ${ }^{3}$ M.M.I. srl, Milan, Italy
}

Correspondence to: A. Ceppi (alessandro.ceppi@polimi.it)

Received: 21 November 2013 - Published in Hydrol. Earth Syst. Sci. Discuss.: 23 December 2013

Revised: 4 July 2014 - Accepted: 23 July 2014 - Published: 5 September 2014

\begin{abstract}
In recent years frequent periods of water scarcity have enhanced the need to use water more carefully, even in European areas which traditionally have an abundant supply of water, such as the Po Valley in northern Italy. In dry periods, water shortage problems can be enhanced by conflicting uses of water, such as irrigation, industry and power production (hydroelectric and thermoelectric). Furthermore, in the last decade the social perspective in relation to this issue has been increasing due to the possible impact of climate change and global warming scenarios which emerge from the IPCC Fifth Assessment Report (IPCC, 2013). Hence, the increased frequency of drought periods has stimulated the improvement of irrigation and water management.

In this study we show the development and implementation of the PREGI real-time drought forecasting system; PREGI is an Italian acronym that means "hydrometeorological forecast for irrigation management". The system, planned as a tool for irrigation optimization, is based on meteorological ensemble forecasts (20 members) at medium range (30 days) coupled with hydrological simulations of water balance to forecast the soil water content on a maize field in the Muzza Bassa Lodigiana (MBL) consortium in northern Italy. The hydrological model was validated against measurements of latent heat flux acquired by an eddy-covariance station, and soil moisture measured by TDR (time domain reflectivity) probes; the reliability of this forecasting system and its benefits were assessed in the 2012 growing season. The results obtained show how the proposed drought forecasting system is able to have a high reliability of forecast at least for 7-10 days ahead of time.
\end{abstract}

\section{Introduction}

A lack of water has always been one of the most critical factors for the survival of populations around the world. The United Nations proclaimed the year 2003 as the international year of freshwater and the year 2006 as the international year of deserts and desertification, highlighting the importance of prevention, mitigation and adaption of events related to water supply. Future climate change scenarios combined with limited water resources require better irrigation management and planning (English et al., 2002; Farrè and Faci, 2009); this has also occurred in areas habitually with an abundant supply of water as the Po Valley in the north of Italy. Considering historical climate data sets, recent studies demonstrate that there is not a significant decrease in the amount of precipitation, although a reduction in the last 20 years has been found over Italy (Salerno et al., 2007). However, a new and more frequent distribution of extreme events has been observed (Maugeri, 2006), as occurred in the most recent drought episodes of the years 2003, 2005 and 2006 in the Lombardy region (Craveri, 2006).

Scientific literature provides interesting issues focused on the optimization of irrigation management also coupling meteorological and hydrological models. Examples of main international research are the CROPWAT (a computer program for irrigation planning and management) by Smith (1992), the EPIC-PHASE (Erosion Productivity Impact Calculator-phase) model developed at the centre of Toulouse (Cabelguenne et al., 1997), the real-time scheduled irrigation approach proposed by Gowing and Ejieji (2001) in the United Kingdom, the "eWarning" Danish warning system (Jensen and Thysen, 2003), real-time forecasts for daily evapotranspiration proposed by Cai et al. (2007) and 
the Canterbury Irrigation Scheduler (CIS) by Brown et al. (2010). In the north of Italy the recurrence of water stress periods requires an improvement in the management and coordination of water courses (lakes, hydroelectric reservoirs, rivers, etc.), together with testing other alternative sources, such as water withdrawals from large quarry lakes (Ravazzani et al., 2011a). This activity has contributed to the better management of water distribution by water consortia according to season, different cultivation requests and total available water in lakes and snowpack. A prudent water distribution policy means wiser and thriftier methods of irrigation, maximizing agricultural production (Hassanli et al., 2009; Oweis and Hachun, 2009; Geerts and Raes, 2009). However, these management policies are currently based on the sensitivity and experience of consortia managers. A policy of saving irrigation water would be helpful if districts were subsequently affected by significant rainfall, but extremely dangerous if no precipitation occurs in the following weeks.

It is clear that the complexity of these matters related to water resources should be studied with a scientific and engineering approach, in order to be able to predict the occurrence of potentially harmful droughts in advance; this issue is also one of the main goals of the DROUGHT R\&SPI (Fostering European Drought Research and Science-Policy Interfacing, www.eu-drought.org) and DEWFORA (Drought Early Warning and Forecasting to strengthen preparedness and adaptation to droughts in Africa, www.dewfora.net) projects, which focus on drought early warning systems respectively on the European and African continents.

Scientific literature proposes different methods, more related to statistical approaches, for optimizing irrigation scheduling and planning (Kuo and Liu, 2003; Negesh Kumar et al., 2006; Azamathulla et al., 2008; Vico and Porporato, 2011, 2013), while the application suggested in this paper takes into account actual measures of soil moisture and observed weather data in addition to updated forecasts to provide landowners with a suitable product for real-world farm profit optimization, as well as cost savings for irrigation practices: e.g. water volume, pumping system from ditches, fuel for tractors and labour costs. Our task is to put the scientific know-how into practice as a tool for better irrigation management and planning. In fact, working on the PREGI project (PREGI is an Italian acronym that means "hydrometeorological forecast for irrigation management"), funded by the Lombardy region in the years 2010-2012, we discovered how irrigation practices in the Po Valley area are left to very old strategies more related to landowner experiences rather than scientific studies and engineering processes. In this context, an adoptable methodology is the one applied for real-time flood predictions (Rabuffetti et al., 2008; Ceppi at al., 2013), coupling meteorological forecasts with hydrological simulations. The knowledge of quantitative precipitation forecasts (QPFs) for the following weeks combined with the updating of hydrological conditions makes it possible to obtain a tool for water distribution management in cultivated areas in order to improve irrigation scheduling, minimize irrigation costs and save water; therefore, to comply with this aim, our idea was to create a web application where farmers are able to monitor real-time soil moisture conditions and forecasts.

The PREGI system is based on meteorological forecasts at medium range with hydrological simulations of water balance to forecast the soil moisture at field scale. In particular, three TDR (time domain reflectivity) probes were installed to monitor soil moisture conditions, while to produce probabilistic soil moisture forecasts, the non-hydrostatic WRFARW (Weather Research and Forecasting-Advanced Research WRF) meteorological model based on 20 ensemble members with 1 month as the forecast horizon provided by Epson Meteo Centre (EMC) was coupled with the FESTWB (Flash-flood Event-based Spatially distributed rainfallrunoff Transformation-Water Balance) distributed hydrological model developed at Politecnico di Milano (POLIMI), and used to generate soil moisture simulations.

The area of study is a maize field in the Muzza Bassa Lodigiana (MBL) consortium in the Po Valley (northern Italy), used as an experimental test site for the PREGI tool. A calibration phase was carried out for the 2010 and 2011 growing seasons, while a validation was performed in the 2012 season, when it was also possible to couple hydrological simulations with meteorological forecasts in order to obtain soil moisture predictions; the results of this forecasting chain show a high reliability of up to 7-10 days as the lead time of forecasts. Notwithstanding this, during the 2012 season the PREGI system was not fully employed by the landowner of the experimental field, and the decision-making criteria did not follow the indications highlighted in the PREGI platform; in fact, as shown in Sect. 3.3, a better management of water distribution could have been carried out and even one scheduled irrigation could have been saved.

\section{Case study, models and methods}

\subsection{Area of study}

The territory of the MBL consortium covers an area of $740 \mathrm{~km}^{2}$ in which there are more than 150 irrigation basins and thousands of irrigation subbasins, which include the private lots of landowners (Fig. 1). Inside the MBL basin, which is composed of open-earth canals, the Muzza channel (about $40 \mathrm{~km}$ long) derives water from the Adda River at Cassano d'Adda, and it flows back into the Adda close to Castiglione d'Adda. It is both the largest irrigation canal in terms of capacity and the first artificial canal built in northern Italy: 38 intakes and many more hydraulic nodes are included along the canal.

Average annual rainfall measured in the MBL consortium range from 800 (southern area) to $1000 \mathrm{~mm}$ (northern area) 


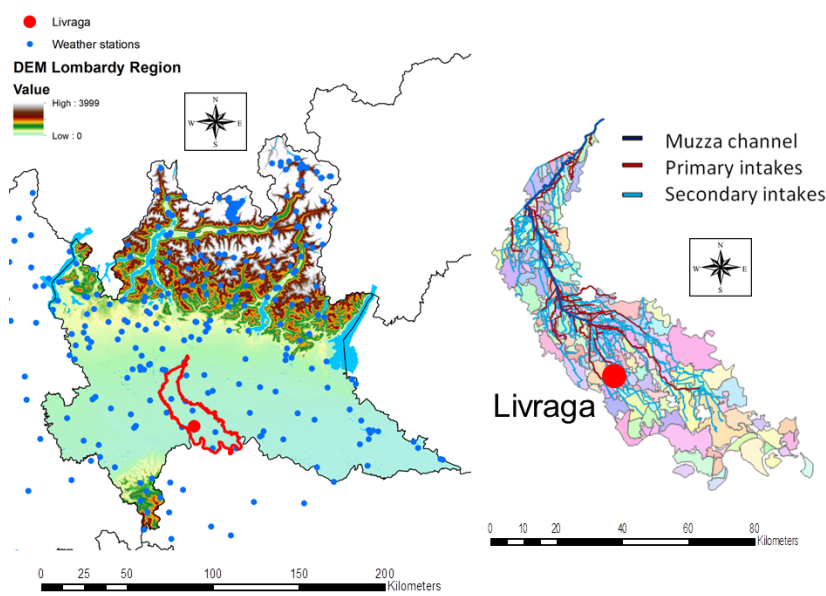

Figure 1. The Lombardy region in the north of Italy (left) and the MBL consortium with its irrigation subbasins (right). The Livraga test site is shown with a red dot, while the available rain gauge stations of the Lombardy ARPA and Meteonetwork-EMC network used as input into the FEST-WB hydrological model are shown with blue dots.

with two peaks in spring and autumn (Ceriani and Carelli, 2000). During the summer season most of the water supply comes from the irrigation network. The upper-medium part of the basin is irrigated by flowing surface water, while, in the bottom part of the basin, water is taken and lifted by the Adda and Po rivers through proper pumping systems.

The experimental test site for the PREGI project is a field located in the middle of the MBL basin at Cascina Nuova farm in the town of Livraga, where meteorological, eddycovariance stations and TDR probes for evapotranspiration fluxes and soil moisture profile, respectively, have been installed to measure hydrological processes (Masseroni et al., 2012). Since no measures in other consortium fields were available to calibrate and validate the hydrological model, it was not possible to verify the PREGI forecasting system outside the Livraga experimental site. Notwithstanding this, such a system can be replicated in any geographical area and vegetated field, on the condition that soil features, weather, hydrological data and irrigation time allotments are available.

\subsection{Meteorological model}

The probabilistic forecast was provided by the Regional Ensemble Prediction System (REPS), based on the WRF-ARW model, implemented and developed by the EMC. The REPSWRF used in this project has a grid mesh size of $18 \mathrm{~km}, 36$ vertical levels and 20 members; boundary and initial conditions are provided by the Global Ensemble Prediction System (GEPS) based on a modified version of the WRF-ARW applied at the global scale, which has a grid mesh size of $200 \mathrm{~km}$ and the same number of vertical levels as the REPS, and it uses the same initial conditions in the control runs provided by the 12:00 UTC GFS (Global Forecasting System) analysis at $0.5^{\circ}$ of horizontal resolution. The forecast has a lead time of 30 days, while the temporal resolution is $12 \mathrm{~h}$. Each perturbation of the ensemble is produced by an algorithm developed by the EMC based on a special application of ensemble transform Kalman filter (EnTKF), able to allow covariance localization whilst maintaining computational efficiency and removing spurious long-range correlations. The REPS-WRF is carried out every 2 days, since this is the computational time to run the combined system. The REPS-WRF run starts at 00:00 UTC, the same start time as the hydrological simulation. For a detailed description of the WRF model, please refer to Skamarock and Klemp (2008).

\subsection{Hydrological model and required data}

In this study, hydrological simulations are performed using the FEST-WB, a rainfall-runoff spatially distributed and physically based model, whose development was initiated by the Politecnico di Milano in 1990.

The FEST-WB calculates the main processes of the hydrological cycle: evapotranspiration, infiltration, surface runoff, flow routing, subsurface flow, snow dynamics and soil water content. The model requires observed precipitation and air temperature data from ground stations, which are both interpolated to a regular grid using the inverse distance weighting technique or forecasted weather data. The spatial domain is discretized with a mesh of regular square cells $(200 \mathrm{~m}$ in this application), while the temporal resolution of soil moisture simulations and forecasts is calculated on a daily timescale; since the Livraga maize field is about 8 ha wide and the landowner schedules his activities on daily/weekly planning, both the spatial and timescale turned out to be appropriate from a computational time point of view.

In addition to (observed/forecasted) weather data, the hydrological model needs further information to be set up, such as land use, soil texture, hydraulic conductivity (Ks), type of vegetation (dates of sowing and harvest), DEM (digital elevation model), aquifer parameters and scheduled irrigations. In particular, amounts and methods of water allotments are fundamental to keep updated soil moisture initial conditions. In fact, since irrigation allotments are planned by the MBL consortium, landowners cannot irrigate their fields on days other than the scheduled ones, because each field of the Muzza consortium has its own scheduled irrigation following centuries-old time tables where planned water allotments are determined in advance; therefore, this information becomes mandatory in the hydro-meteorological forecasting chain. At the Livraga experimental field this is available every week; i.e. the landowner has the possibility of withdrawing water from the nearest irrigation ditch every 7 days. For instance, the potential water concession for the Cascina Nuova farm is $650 \mathrm{~L} \mathrm{~s}^{-1}$ taken from the "Porra Nuova" ditch, but, considering that the irrigation efficiency of the Muzza basin is about $45 \%$ of the theoretical value, the available water discharge is 
only about $300 \mathrm{~L} \mathrm{~s}^{-1}$. Since this volume of water is used to irrigate our experimental field of 8 ha in about $8 \mathrm{~h}$, the estimated irrigation input implemented in the FEST-WB model was assumed to be equal to $108 \mathrm{~mm}$.

As far as soil information is concerned, in situ field tests carried out during the PREGI project have classified the soil texture as silt loam; in particular, a content of $19.2 \%$ clay, $48.1 \%$ silt and $32.7 \%$ sand was found in soil analyses. Table 1 summarizes the main soil properties for the Livraga maize field: a tuning of these values inside the interval range reported in Maidment (1993) was carried out to calibrate and implement the FEST-WB hydrological model.

Another important parameter to define in the hydrological model is soil depth, which has been modelled as a single layer with a value of $0.7 \mathrm{~m}$, considering the predominant growing zone of maize roots; consequently the three TDR probes were installed at 10,35 and $70 \mathrm{~cm}$ depth. Finally, different measures of permeability were performed with the Guelph infiltrometer (Eijkekalmp, 2011) to investigate the $\mathrm{Ks}$, which was found to be equal to $2.36 \times 10^{-7} \mathrm{~m} \mathrm{~s}^{-1}$ in the experimental field.

As described in the results (Sect. 3), observed and forecasted soil moisture data are influenced by rainfall, irrigation contributions and evapotranspiration fluxes which denote main inflows and outflows in water balance at the Livraga field scale. Evapotranspiration losses play a crucial role in the water balance during the summer season in the Po Valley area where cumulated values exceed $300 \mathrm{~mm}$ in 4 months (see Figs. 2b, d, f). Eddy-covariance measures were used to control actual evapotranspiration (ET) fluxes and to make a comparison with the ET simulated by the FEST-WB model (see Sect. 3.1 for further details). When eddy-covariance measures are not available, the system target would not in any case be affected, since the main hydrological variable is the soil moisture, and TDR probes are sufficient for monitoring and forecasting purposes. However, the limits of such a system, in order to be replicated in other areas, are the availability of real-time data (weather and soil moisture values), amounts and scheduled irrigation allotments.

In the current version of the FEST-WB model, evapotranspiration is computed according to a revised version of the Food and Agricultural Organization (FAO-56) method (Allen et al., 1998). The original approach is based on the use of the Penman-Monteith equation (Monteith, 1965) to calculate a reference evapotranspiration $\left(\mathrm{ET}_{0}\right)$ of a surface defined as an "hypothetical crop with an assumed height of $0.12 \mathrm{~m}$, having a surface resistance of $70 \mathrm{~s} \mathrm{~m}^{-1}$ and an albedo of 0.23 , closely resembling the evaporation of an extensive surface of green grass of uniform height, actively growing and adequately watered" (Allen et al., 1998). In this paper, due to the availability of only air temperature meteorological forecasts, the Penman-Monteith equation is substituted with a modified Hargreaves and Samani equation (Hargreaves and Samani, 1985) which includes a correction factor for altitude (Ravazzani et al., 2012). In Ravazzani et al. (2012), the reliability of this modified equation to compute $\mathrm{ET}_{0}$ has been demonstrated. Subsequently, the crop coefficient $\left(k_{\mathrm{c}}\right)$, which embodies all the physiologic characteristics of a specific plant, allows passing from $\mathrm{ET}_{0}$ to the potential evapotranspiration of a specific crop. Allen et al. (1998) created a database of $k_{\mathrm{c}}$ for a large number of agricultural crops in different climates, including maize. Crop coefficient values are assigned by defining the length of phenological phases considering the sowing and reaping dates for each year. For further details about the development and calibration of the FEST-WB, please refer to Montaldo et al. (2003, 2007), Ravazzani et al. (2007, 2011b), Corbari et al. (2011) and Ravazzani (2013).

\subsection{Coupling strategy and warning thresholds}

The cascade forecasting system applied in this study is currently based on hydrological model initialization from meteorological model output: temperature and precipitation forecasts.

Before launching the coupled system, the hydrological model is initialized with observed weather data of the previous day, provided by the ARPA (Regional Agency for Environmental Protection) of the Lombardy region and Meteonetwork-EMC meteorological station network to set up the initial soil moisture conditions. In order to better understand the developed forecasting chain, an example of each step of the operative chain is detailed in Table 2.

This coupling of hydro-meteorological models to irrigation scheduling knowledge provides advance information on soil moisture content and expected cumulated precipitation for irrigation management and water control from 1 to 30 days as a forecast horizon.

In order to issue warnings regarding soil moisture forecasts, two thresholds were defined in the PREGI system: one is the water surplus equal to the field capacity of the soil and the other is the stress threshold, where below this point the crop begins to suffer because of a lack of water. According to the FAO-56 definition (Allen, et al., 1998) and also applied in Baroni et al. (2010) the latter is calculated as follows (1):

$\mathrm{RAW}=p \cdot \mathrm{TAW}$,

where RAW is the readily available water, defined as field capacity minus stress threshold; TAW is the total available water, defined as field capacity minus wilting point; and $p$ is a coefficient depending on the crop and climatic parameters which can be assumed to be equal to 0.5 for maize (Allen et al., 1998) in the Livraga field. Therefore, the Eq. (1) becomes

field capacity - stress threshold

$$
=p \cdot(\text { field capacity }- \text { wilting point }) .
$$


Table 1. Water-retention properties classified for a silt loam soil type (Maidment, 1993).

\begin{tabular}{lrrrrr}
\hline $\begin{array}{l}\text { Total } \\
\text { porosity }(\phi)\end{array}$ & $\begin{array}{r}\text { Residual water } \\
\text { content }\left(\theta_{\mathrm{r}}\right)\end{array}$ & $\begin{array}{r}\text { Pore size } \\
\text { distribution }(\lambda)\end{array}$ & $\begin{array}{r}\text { Wilting } \\
\text { point }\end{array}$ & $\begin{array}{r}\text { Field } \\
\text { capacity }\end{array}$ & $\begin{array}{r}\text { Bubbling } \\
\text { pressure }\left(h_{\mathrm{b}}\right)\end{array}$ \\
\hline 0.501 & 0.015 & 0.234 & 0.133 & 0.330 & 0.2076 \\
\hline
\end{tabular}

a)

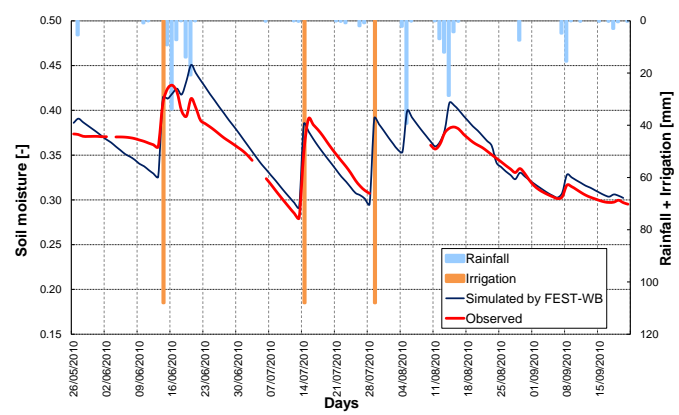

c)

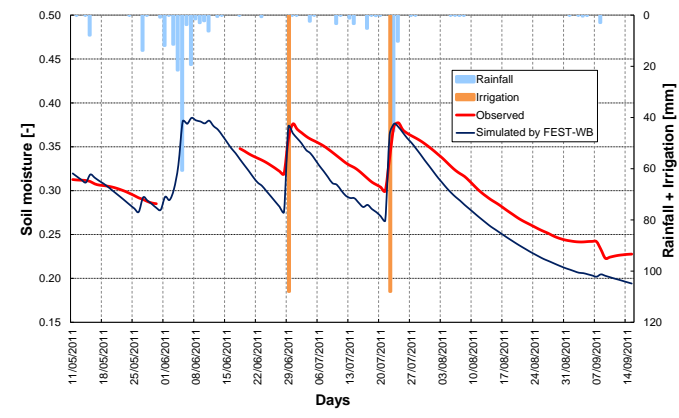

e)

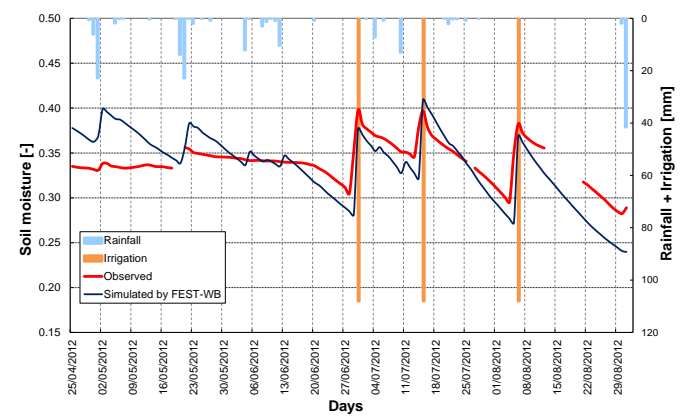

b)

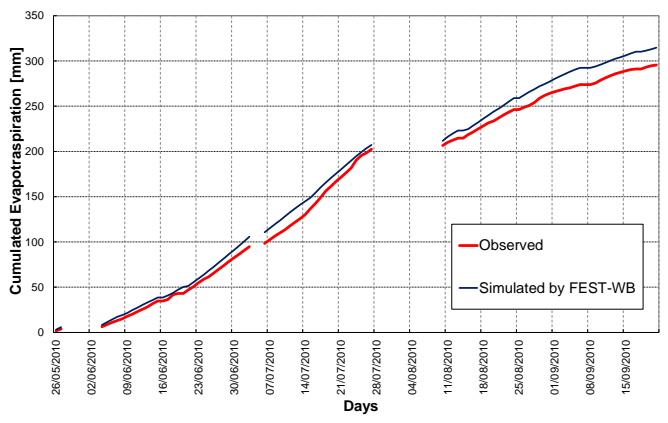

d)

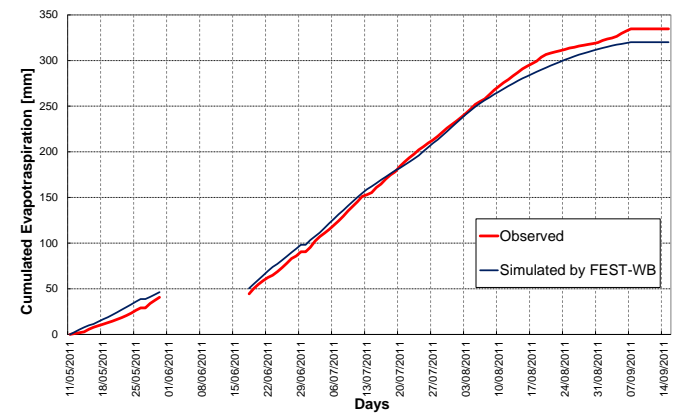

f)

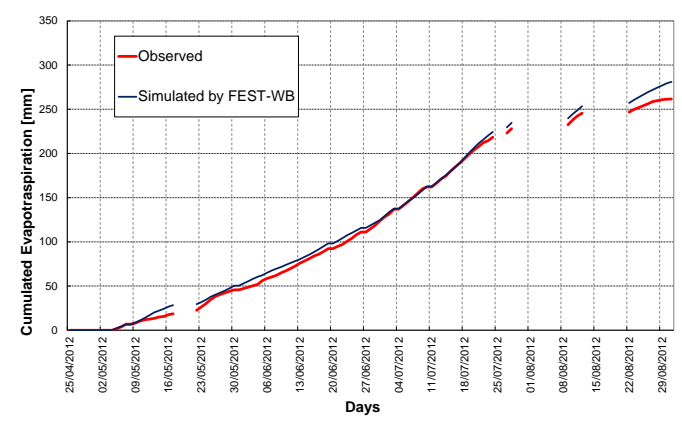

Figure 2. The left graphs (a, c, e) show the comparison between observed (red line) and simulated (blue line) soil moisture values by the FEST-WB model at the Livraga maize field for the 2010, 2011 and 2012 growing season; precipitation (blue bars) and irrigation (orange bars) amounts are shown in light-blue histograms. The right graphs (b, d, f) show the comparison between observed (red line) and simulated (blue line) actual cumulated evapotranspiration values by the FEST-WB model. Unfortunately, some observed data are missing due to storage battery problems in the 3-year project.

Substituting the values of 0.33 and 0.13 respectively for field capacity and wilting point for the Livraga silt loam soil (see Sect. 2.4), the Eq. (3) becomes

stress threshold $=0.33-0.5 \cdot(0.33-0.13)$.
Hence, the stress threshold value we are looking for is equal to 0.23. As described in Sect. 3.3, this stress threshold is a decision criterion in order to plan whether or not to irrigate on the days when water allotment is available. 
Table 2. Description of the forecasting chain coupling the meteorological and hydrological model. The action time is reported in UTC (Coordinated Universal Time), while the time delay after the first step of the operative chain is reported in hours and minutes (hh:mm).

\begin{tabular}{lrl}
\hline $\begin{array}{l}\text { Day and } \\
\text { time } \\
\text { [UTC] }\end{array}$ & $\begin{array}{r}\text { Time delay after } \\
\text { the start of the } \\
\text { chain [hh:mm] }\end{array}$ & Action \\
\hline Day 1 at 00:00 & - & The REPS-WRF model is launched by the EMC \\
\hline Day 3 at 12:00 & $60: 00$ & The REPS-WRF model outputs are uploaded on the POLIMI server \\
\hline Day 3 at 13:00 & $61: 30$ & $\begin{array}{l}\text { Observed weather data of the previous day provided by the Lombardy ARPA } \\
\text { and Meteonetwork-EMC meteorological station network are available on the } \\
\text { POLIMI server }\end{array}$ \\
\hline day to produce initial conditions
\end{tabular}

\subsection{Statistical indexes}

Common skill scores in scientific literature are used to compare soil moisture simulations between observed and simulated values by the FEST-WB model initialized with observed values and weather data forecasted by the REPSWRF model; since the WRF is a probabilistic model with 20 ensemble members, the median value is chosen for analysis clarity. In particular, results described in Sect. 3.2 include the mean relative error (MRE) - calculated as (Eq. 4)

$\mathrm{MRE}=\frac{1}{n} \sum_{i=1}^{n}\left(\frac{F_{i}-O_{i}}{O_{i}}\right)$,

where $O_{i}$ represents observed values, $F_{i}$ represents median of forecasted values and $n$ represents numbers of analysed events - and the NS index (Nash and Sutcliffe, 1970):

$\mathrm{NS}=1-\frac{\sum_{i=1}^{n}\left(O_{i}-F_{i}\right)^{2}}{\sum_{i=1}^{n}\left(O_{i}-\bar{O}\right)^{2}}$

where $\bar{O}$ represents the average of observed values, which shows how well the forecast predicts the observed time series, with best scores close to 1 , and a range between $-\infty$ and 1. In this study, Eq. (5) measures the ratio between the deviations of forecasted median values by the FEST-WB hydrological model initialized by 20 ensembles of the REPSWRF model with observed values and the deviation between the observed mean and observed values.

Another skill score used in this study is the Brier score (BS), which is essentially the mean-squared error of the probability forecasts, considering that the observation is $o=1$ if the event occurs and $o=0$ if the event does not occur. The score averages the squared differences between pairs of forecast probabilities and the subsequent observations (Wilks, 2006). Equation (6) for the BS score is

$\mathrm{BS}=\frac{1}{n} \sum_{k=1}^{n}\left(F_{k}-O_{k}\right)^{2}$,

where $N$ represents number of forecasting instances, $F_{k}$ represents the probability that an event was forecasted and $O_{k}$ represents the actual outcome of the event at instance $k(0$ if it does not happen and 1 if it happens).

For instance, supposing that the forecast probability to exceed a threshold of cumulated rainfall is $70 \%$ and then this event occurs, the BS score is equal to 0.09 ; vice versa, if it does not occur, then the BS score is 0.49; therefore, best scores are close to 0 . In this analysis, three thresholds were chosen: 20, 50 and $100 \mathrm{~mm}$; these last two values are reasonably similar to half and full irrigation in the Livraga maize field, while the $20 \mathrm{~mm}$ threshold corresponds to typical precipitation amounts in that area, which is not usually affected by heavy rainfall in the summer season, as occurred in 2012 . It is important to bear in mind that this computation, performed with the entire forecast data set, does not refer to daily precipitation values, but rather cumulated precipitation values over a period of 1, 2, 3, ., 30 days. For instance, the BS score at the the 7th day as the lead time considers the occurrence probability of a cumulated precipitation forecast over a period of 7 days to exceed the threshold of 20,50 or $100 \mathrm{~mm}$ (occurring over the same time period of 7 days). 


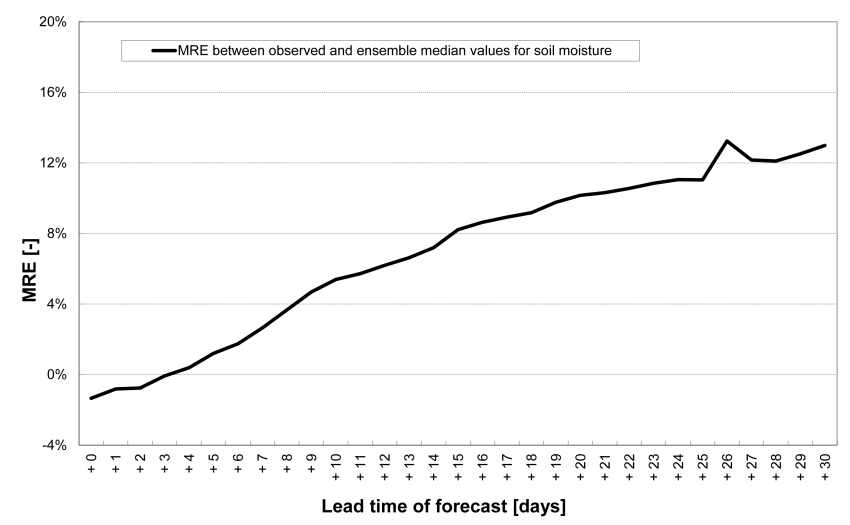

Figure 3. The mean relative error for soil moisture between the observed data and the median of all the FEST-WB simulations initialized with the 20 ensembles of the REPS-WRF model for the 2012 growing season over a period of more lead time days.

\section{Results and discussion}

\subsection{Calibration and validation of the FEST-WB model using observed data}

The 2010-2012 period was used to calibrate and validate the hydrological model with data acquired at Cascina Nuova field in Livraga, where one eddy-covariance station and three TDR probes were installed to monitor evapotranspiration fluxes and soil moisture content. Figure 2 shows the comparison between values measured (red line) by TDR probes (in reality, it is a weighted average of the three measures at a depth of 10,35 and $70 \mathrm{~cm}$ ) and data simulated (blue line) by the FEST-WB model during the three growing seasons of 2010, 2011 and 2012, including rainfall (light-blue bars) and irrigation (orange bars) amounts in the Livraga maize field.

As far as the 2010 season is concerned, Fig. 2a shows how soil moisture data are well associated with rainfall and irrigation inputs, with a MAE of $4 \%$ and MRE of $+1 \%$; a good match between observed and modelled simulation data is also shown in Fig. 2b for the actual cumulated evapotranspiration. In addition, Fig. 2a shows how the first seasonal irrigation (14 June 2010) could have been avoided if soil moisture and precipitation forecasts had been known in advance; in fact, severe rainfall (about $85 \mathrm{~mm}$ ) occurred between 15 and 20 June, with a maximum peak of $45 \mathrm{~mm}$ on 15 June (the day after the irrigation!). Unfortunately, in that year the PREGI tool with hydro-meteorological forecasts was not yet in service and it was only available for the 2012 vegetation season.

In regard to the 2011 season, satisfactory results are found between observed and simulated values in terms both of soil moisture (MAE equal to $8 \%$, Fig. 2c) and cumulated evapotranspiration (Fig. 2d), even if an underestimation is generally present (MRE of $-8 \%$ ) in simulated soil moisture values, mainly due to higher rates in evapotranspiration.

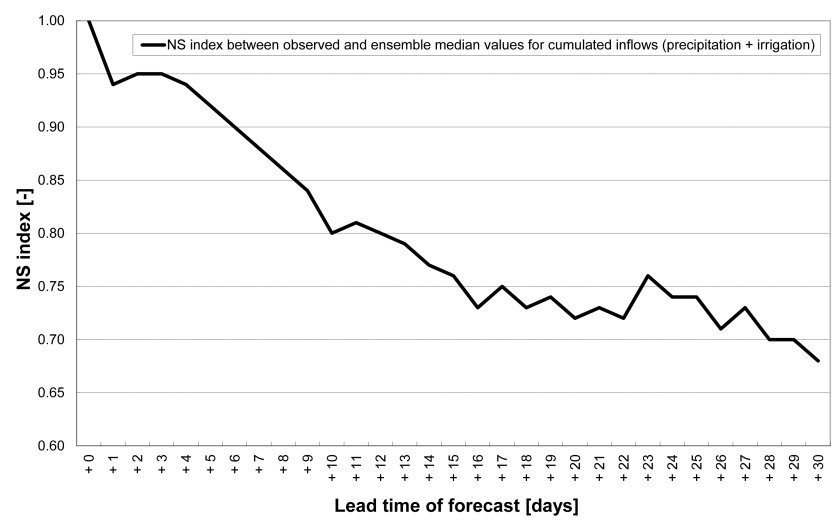

Figure 4. The NS index for rainfall and irrigation amounts between the observed data and the median of 20 ensembles of the REPSWRF model for the 2012 growing season over a period of more lead time days.

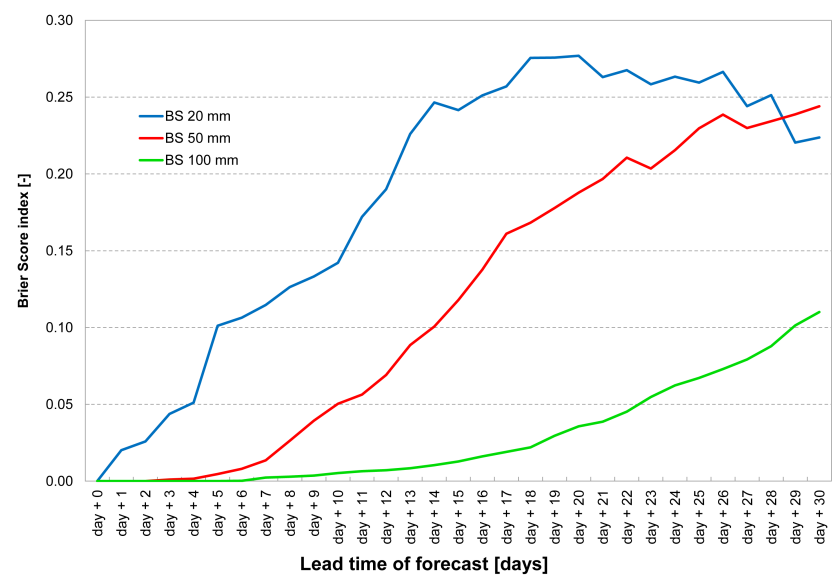

Figure 5. Brier score index for the three thresholds of cumulated rainfall: $20 \mathrm{~mm}$ (blue line), $50 \mathrm{~mm}$ (red line) and $100 \mathrm{~mm}$ (green line) for the 2012 growing season over a period of more lead time days.

After 2 years of calibration (2010 and 2011), the validation of the FEST-WB model is carried out for the 2012 growing season at the Livraga field. The performance of the validation (Fig. 2e) shows a good match between model and observations, with a MAE of $7 \%$ and MRE of $-1 \%$. A slight underestimation of the FEST-WB is generally present except at the beginning of the season; however, the hydrological model, initialized with observed values by the Lombardy ARPA and Meteonetwork-EMC weather stations, was able to simulate soil moisture conditions with a daily error within $10 \%$, in particular during the irrigation period between June and $\mathrm{Au}-$ gust. Even the comparison between observed (red line) and simulated (blue line) data for the real cumulated evapotranspiration (Fig. 2f) indicates a good correspondence during the 2012 growing season. 
a)

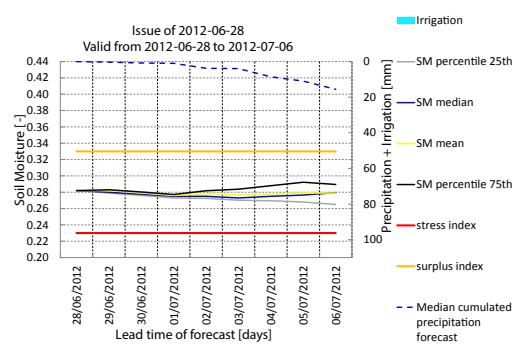

c)

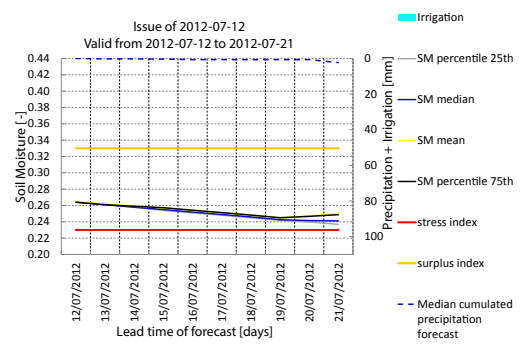

e)

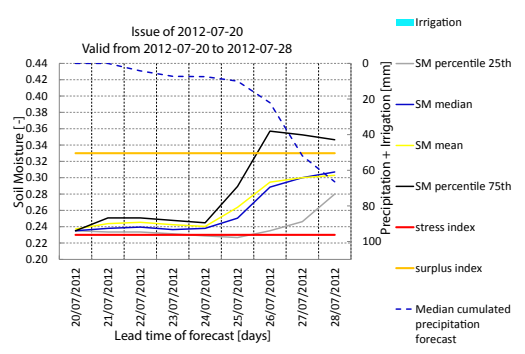

g)

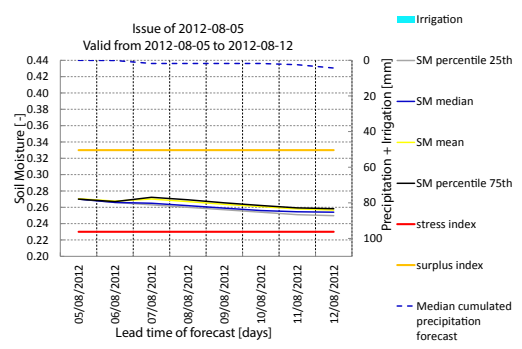

i)

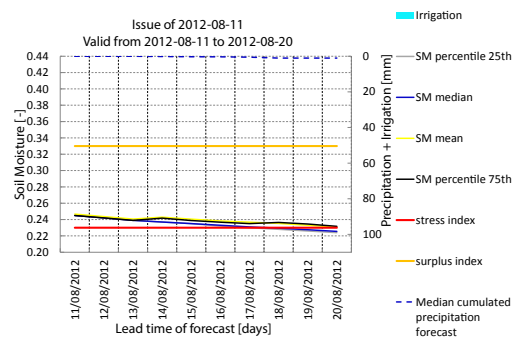

b)

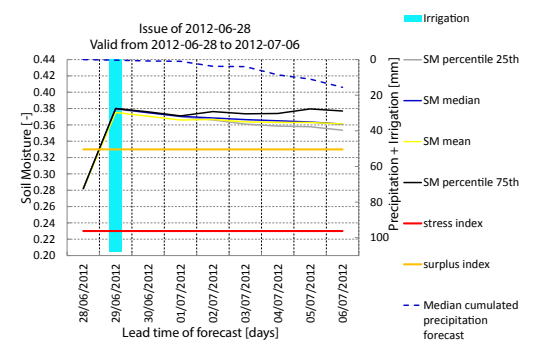

d)

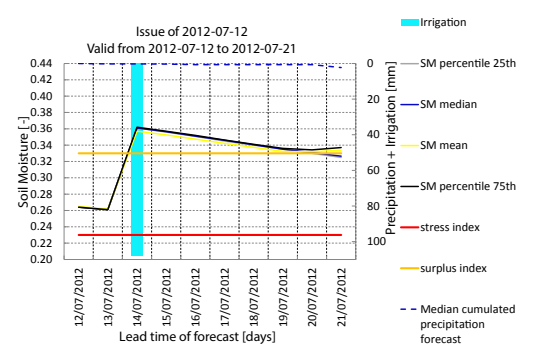

f)

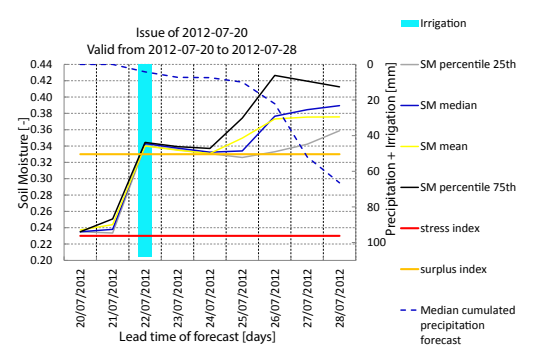

h)

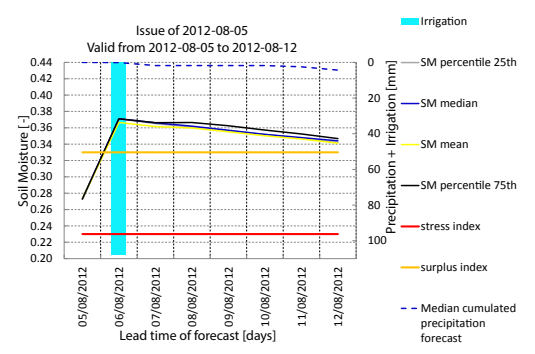

j)

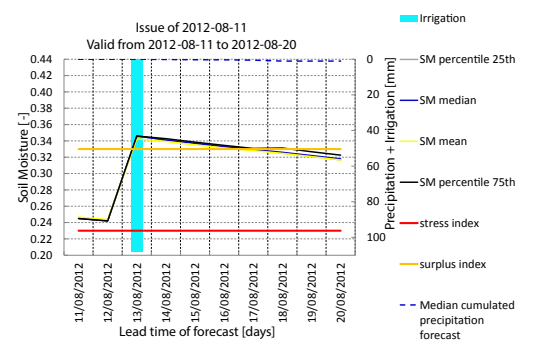

Figure 6. Soil moisture forecasts issued on 28 June (a-b), 12 July (c-d), 20 July (e-f), 5 August (g-h) and 11 August (i-j) without planning irrigations (left) and with including irrigation amounts in simulations (right). For the sake of clarity, only the mean (yellow line), the median (solid blue line) and the 25th and 75th percentile (respectively grey and black lines) are shown; the median of forecasted precipitation is shown with a dashed blue line, while the scheduled irrigations are shown with light-blue bars. 


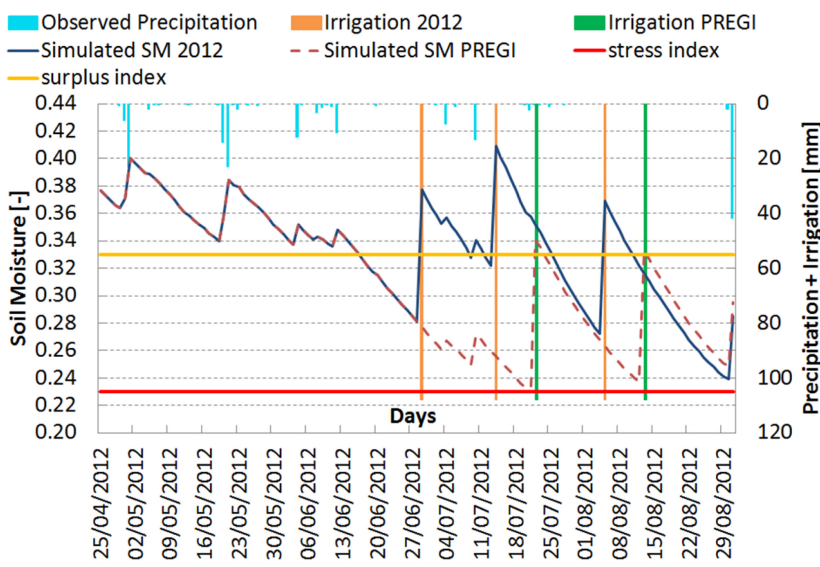

Figure 7. Comparison between simulated soil moisture by the FEST-WB model assuming that the landowner had followed his decision criteria (blue line) with three actual irrigations (orange bars) in 2012, and if the farmer had followed the PREGI system (dashed brown line) with two hypothetical irrigations (green bars); the observed rainfall is shown with light-blue bars.

\subsection{Evaluation of the PREGI performance coupling meteorological and hydrological forecasts}

Indeed, one of the main goals of the PREGI project was to couple weather and hydrological models to provide soil moisture forecasts as a support decision system for the irrigation optimization in the 2012 season on the Livraga maize field. The hydro-meteorological chain was set up using the REPS-WRF output provided by the EMC in the FEST-WB hydrological model developed by the POLIMI. The REPSWRF model output was available every 2 days, and therefore the data set includes 90 days of simulations between 27 February and 31 August 2012. Since the weather model has a forecast horizon of 30 days, in order to value the forecasting chain, the statistical analysis has been carried out starting from "day +0 ", i.e. the forecast at the same day of the initialization date run, up to "day+30". For instance, a skill score value for the "day +10 " considers all forecast performances at 10 days (as the lead time) from the initialization date. The statistical analysis in this paper was performed using common skill scores known in the literature (Wilks, 2006; Jolliffe and Stephenson, 2003).

As Figs. 3 and 4 show, the forecast reliability tends to diminish by increasing the forecast horizon. However, a good performance is achieved up to 10-15 days for soil moisture forecasts (Fig. 3) and up to the first week for cumulated rainfall forecasts by the REPS-WRF model (Fig. 4).

In particular, Fig. 3 shows the MRE between observed and simulated values by the FEST-WB initialized with the REPSWRF model output. The MRE is around $\pm 2 \%$ in the first 6 days of the forecast horizon, while an overestimation in the FEST-WB simulations initialized with the REPS-WRF weather forecasts is shown in the remaining period $(+8 \%$ at

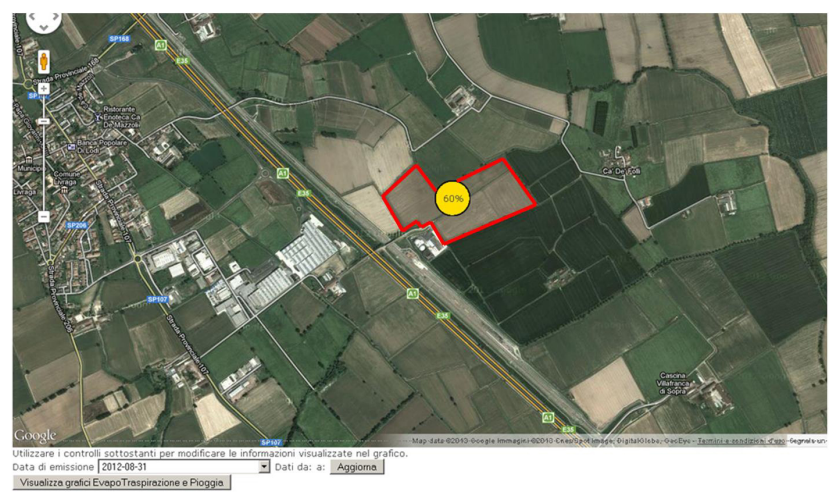

Figure 8. View of the Google Maps platform of the PREGI project. The Cascina Nuova field in Livraga is outlined in red. This example shows $60 \%$ probability (i.e. 12 ensembles out of 20) of exceeding the surplus threshold in at least 1 of the subsequent 30 days, with the forecast simulation started on 31 August 2012.

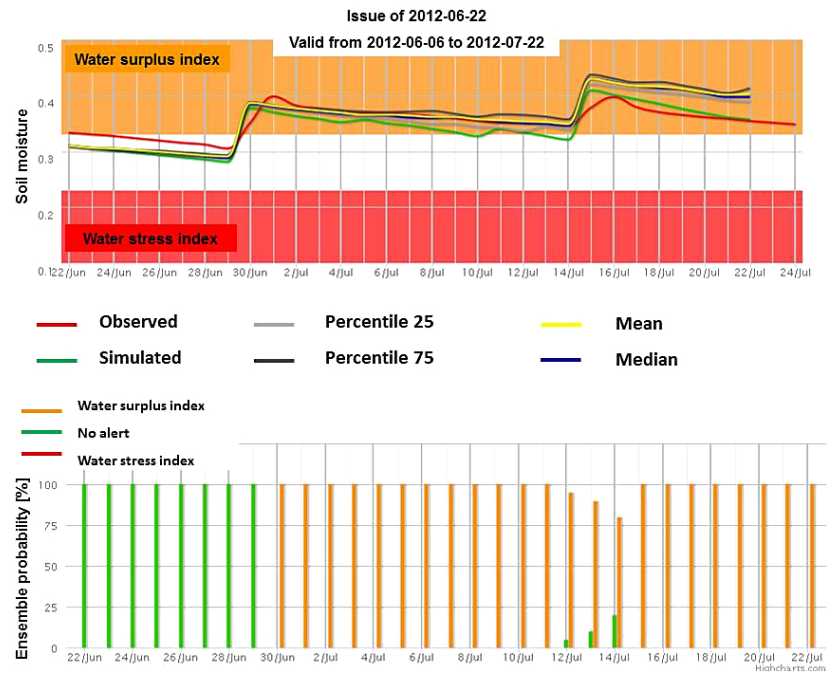

Figure 9. Soil moisture re-analysis forecast initialized on 22 June 2012 and valid until 22 July 2012. The red line shows the average value of soil moisture measured with three TDR probes; the green line shows the simulated soil moisture using the FEST-WB model initialized with observed data; and the grey, blue, black and yellow lines show the forecasted soil moisture value by the FESTWB model initialized with the REPS-WRF meteorological model respectively for the 25 th, 50 th and 75 th percentile and the mean.

"day+15"). Even at "day+20" the MRE still remains around $+10 \%$, indicating a good forecast reliability by the REPSWRF model in the 2012 season we analysed.

The NS index shown in Fig. 4 highlights the high performance of the meteorological forecast in the first days of the forecast horizon (NS index greater than 0.90) with a progressive decrease after day +10 ; however, a good forecast reliability is shown even up to the 10th-15th day after the initialization date of the weather model, with NS values between 0.80 and 0.75 . The reason for calculating the forecast 
performance of the rainfall plus irrigation accumulated in a moving forecast horizon, and not the forecasted amount on a specific day, satisfies one of the aims of the PREGI project: in fact, from an irrigation management point of view, it is more important to know whether the next 7 or 14 days, which usually coincide with water irrigation allotments in the MBL fields, will be wet or dry than whether a precipitation event will occur precisely on the 14th or 15th day of the forecast. However, Fig. 5 shows the REPS-WRF model performance with forecasted precipitation only, excluding the contribution of irrigation, using the Brier score index for a forecast horizon from 1 to 30 days during the 2012 growing season. As is shown in Fig. 5, the forecast performance is better for the threshold of $100 \mathrm{~mm}$ cumulated over a moving period from 1 to 30 days, worsening as the lead time increases. However, the forecast reliability has a different trend for thresholds greater than 50, and above all $20 \mathrm{~mm}$, with higher Brier score values in the first days of lead time and a subsequent worsening in the following period. In fact, in the way in which the BS is defined, the rarer an event, the easier to get a better BS. This is true if we consider the frequency of events which exceed the threshold of $100 \mathrm{~mm}$ cumulated in 1,2 , $3, \ldots, 30$ days that occurred during March-August 2012, and more in general in the summer season in the Po Valley area, in comparison with the cumulated precipitation values (observed/forecasted) of $20 \mathrm{~mm}$, which are much more typical from a climatological point of view for this area; however, there is a good level of reliability (BS values lower than 0.15) within the first 10 days even for a threshold of $20 \mathrm{~mm}$ cumulated in 10 days. Notwithstanding this, our decision to show the performance over a cumulated period of $1,2,3, \ldots$, 30 days is the result of a preliminary investigation carried out with the landowner of the Livraga field, who is the real decision-maker: as mentioned above, from his point of view it was more interesting to know the reliability of a cumulated precipitation forecast over 7 or 10 days and not whether it is going to rain exactly on the 7th or 10th day from the forecast initialization date. Therefore, considering the available 2012 data set only, this skill analysis with the BS index (as for the NS) was performed with forecast values cumulated over a period of more days $(1,2,3, \ldots, 30)$ rather than $24 \mathrm{~h}$ values.

\subsection{To follow or not to follow the PREGI system}

Although the model validation was only performed after the 2012 growing season, hydro-meteorological simulations were set up in real time at the beginning of the 2012 season when the PREGI system issued soil moisture, evapotranspiration and precipitation forecasts every 2 days, providing the landowner with useful information concerning soil conditions for irrigation scheduling. As described in Sect. 2.4, the initial conditions of the hydrological model were updated daily, taking into account observed weather data and irrigation water amounts which were planned during the entire season more on the basis of the landowner' experience than the PREGI system. Three irrigations were planned during the vegetation season 2012: 29 June, 14 July and 6 August: the lattermost was supposed to be the previous week, on 29 July, but the observed soil moisture values and forecasts convinced the landowner to follow the PREGI application and to postpone it for one week. This advice led to an extension of the growing season until the end of August, when a riper maize was harvested two weeks after the originally scheduled date; however, had the PREGI system been fully followed by the landowner, one out of three irrigations would have been even saved. In fact, to demonstrate the benefits of such a forecasting system, we re-ran two simulations, one assuming that the landowner follows the advice provided by the PREGI platform on when to irrigate, and the other assuming that he follows the currently planned decision criteria; as shown in Fig. 6 (where for the sake of clarity we show only the mean, median and the 25 th and 75 th percentile of ensemble forecasts), one out of three irrigations could have been saved! In particular, the irrigation scheduled for 29 June (Fig. 6b) could have been avoided (Fig. 6a), since none of the 20 ensembles would have forecasted a soil moisture value below the stress threshold. According to the forecast shown in Fig. 6c, even the irrigation that occurred on 14 July (Fig. 6d) could have been avoided and postponed for 1 week (Fig. 6f), to when it was really necessary, because soil moisture forecasts, issued on 20 July, gave a probability of $35 \%$ (i.e. 7 ensemble members out 20) of exceeding the stress value if the landowner had not irrigated on the 22nd (Fig. 6e).

In the same way during August, the landowner could have postponed the planned irrigation for 6 August (Fig. 6h) for one week (Fig. 6j), since no members of the ensemble forecast issued a warning (Fig. 6g) for the next 7 days (which is important to bear in mind for the available irrigation time allotment). In fact, if no irrigation occurred in the following 7 days, the forecast issue on 11 August would have forecasted a probability of $50 \%$ to exceed the stress threshold on 17 August (Fig. 6i).

This comparison between the two scenarios, with or without the PREGI system, made it possible to assess the benefits of this system in terms of water savings. Figure 7 shows, in fact, how the soil moisture conditions with only two simulated irrigations, instead of three, would have remained within the range of the two surplus and stress thresholds. However, the three irrigations that actually took place raised the soil water content even further above the surplus threshold for a good part of the 2012 season.

\section{Conclusions}

The aim of the PREGI project is to realize an integrated system by coupling meteorological and hydrological models to monitor and forecast soil water content in order to manage irrigation water more wisely. The test bed of the project was the maize field at Livraga in the MBL consortium, about 
$50 \mathrm{~km}$ south-east of Milan in northern Italy. The hydrometeorological chain to produce ensemble soil moisture forecasts is based on 20 meteorological members of the nonhydrostatic WRF-ARW model with a 30-day lead-time, provided by the Epson Meteo Centre, while the hydrological model used to generate soil moisture simulations is the FEST-WB rainfall-runoff distributed model, developed by the Politecnico di Milano. This contribution made by ensemble forecasts provides probabilistic information with different forecast scenarios to be below or above stress/surplus thresholds. Furthermore, according to crop water consumption determined by the soil type and the degree of saturation, a continuous monitoring of soil water content was carried out during the entire 2012 growing season, with three TDR probes installed.

The results show how it was possible by combining meteorological and hydrological models to have reliable soil moisture forecasts for up to 10 and 14 days respectively, with a mean relative error of less than $10 \%$. Although the PREGI system showed a good level of performance during the 2012 season, decision criteria for when to irrigate were left more to the farmer's experience rather than the hydro-meteorological forecasts. However, thanks to the PREGI system, we highlighted how one of the three irrigations could have been avoided if the landowner had followed the results generated by our application. Thus, the benefits of this project are both direct and indirect: the direct benefits regard the monitoring and forecasting of soil water content according to the current state of soil moisture values and water crop requirements, while the indirect benefits regard the optimization of water irrigations pursuing the best quantitative distribution, in particular periods of water scarcity, in order to minimize production losses caused by water stress due insufficient watering, avoiding the waste of irrigation water as occurred in the 2010 growing season, when the PREGI system was unfortunately not yet in service.
One of the future developments is to extend these analyses over different sites with other case studies during future growing seasons. However, a limit for replicating this system in other areas will be that of obtaining real-time data (weather and soil moisture information), amounts and scheduled irrigation dates, which are usually not easy to acquire in real time. 


\section{Appendix A: The PREGI platform}

During the 2012 growing season, real-time simulation data were uploaded on a Google Maps platform and stored in a database specifically created for the project. An example of the web application realized for the PREGI project is shown in Fig. 8 with a coloured "traffic-light" dot on the Google Maps view of the Cascina Nuova farm. The value displayed on the coloured dot means a higher daily probability value over a period of 30 days. The dot can be red or orange if stress and surplus thresholds respectively exceed $33 \%$ of ensemble forecasts (i.e. at least 7 ensembles out of 20), following the method already used in the MAP D-PHASE project reported in Zappa et al. (2008); if both thresholds are exceeded, a display priority was given to the stress threshold. Otherwise, if none of these two thresholds are exceeded, no alert is forecasted, and a green dot appears on the map; in this way the Livraga landowner has a tool to control real-time warnings regarding soil moisture forecasts for his maize field. An example of simulations uploaded on the web platform during the 2012 season, when the performance of the PREGI system was evaluated, is shown in Fig. 9. Soil moisture simulations by the FEST-WB hydrological model initialized with observed data by the Lombardy ARPA and MeteonetworkEMC station network are shown with a green line, and the forecasted data by the 20 ensembles of the REPS-WRF meteorological model with coloured lines. In this picture, it is evident how the two irrigations planned for 29 June and 14 July 2012 significantly raised the soil moisture values above the water surplus threshold over the following days. For reason of clarity, in Fig. 9 we do not show all 20 ensembles, but only the 25 th percentile, the median, the 75 th percentile and the mean of ensemble forecasts (respectively grey, blue, black and yellow lines); however, all the 20 ensemble members can be selected in the web application. The average soil moisture value measured with TDR probes in the Livraga test bed is shown with a red line for the entire forecast horizon; as described in Sect. 2.4, the area below the stress threshold $(0.23)$ is highlighted in red, while the one above the field capacity point ( 0.33$)$ is shown in orange. 
Acknowledgements. This work was supported by the PREGI project (PREvisione e Gestione Irrigua) and Dote Ricerca Applicata, both funded by the Lombardy region. The authors are grateful to the MBL consortium (E. Fanfani, M. Chiesa and G. Meazza) for their support in digital cartographic maps and irrigation information for the area we studied, and to the Livraga landowner (E. Grecchi) for giving us the possibility of using his maize field as an experimental test site for 3 years. Last but not least, the authors thank the Lombardy region ARPA and the Meteonetwork Association for the provision in weather data.

Edited by: E. Toth

\section{References}

Allen, R., Pereira, L. S., Raes, D., and Smith, M.: FAO, Irrigation and drainage Paper 56, Crop evapotranspiration, Guidelines for computing crop water requirements, 1998.

Azamathulla, Md., H., Wu, F., Ghani, A., Narulkar, S., Zakaria, N., and Chang, C. Comparison between genetic algorithm and linear programming approach for real time operation, J. Hydrol. Environ. Res., 2, 172-181, 2008.

Baroni, G., Facchi, A., Gandolfi, C., Ortuani, B., Horeschi, D., and van Dam, J. C.: Uncertainty in the determination of soil hydraulic parameters and its influence on the performance of two hydrological models of different complexity, Hydrol. Earth Syst. Sci., 14, 251-270, doi:10.5194/hess-14-251-2010, 2010.

Brown, P. D., Cochrane, T. A., and Krom, T. D.: Optimal on-farm irrigation scheduling with a seasonal water limit using simulated annealing, Agr. Water Manage., 97, 892-900, 2010.

Cabelguenne, M, Debaeke, Ph., Puech, J., and Bosc, N.: Real time irrigation management using the EPIC - PHASE model and weather forecasts, Agr. Water Manage., 32, 227-238, 1997.

Cai, J., Liu, Y., Lei, T., and Pereira, L. S.: Estimating reference evapotranspiration with the FAO Penman - Monteith equation using daily weather forecast messages, Agr. Forest Meteorol., 145, 2235, 2007.

Ceppi, A., Ravazzani, G., Salandin, A., Rabuffetti, D., Montani, A., Borgonovo, E., and Mancini, M.: Effects of temperature on flood forecasting: analysis of an operative case study in Alpine basins, Nat. Hazards Earth Syst. Sci., 13, 1051-1062, doi:10.5194/nhess-13-1051-2013, 2013.

Ceriani, M. and Carelli, M.: Carta delle Pecipitazioni medie, massime e minime annue del territorio alpino della regione Lombardia, registrate nel periodo 1891-1990, Servizio Geologico, Ufficio Rischi Geologici Regione Lombardia, 2000 (in Italian).

Corbari, C., Ravazzani, G., and Mancini, M.: A distributed thermodynamic model for energy and mass balance computation: FESTEWB, Hydrol. Process., 25, 1443-1452, 2011.

Craveri, L.: Siccità nel clima lombardo. L'esperienza del 2003, in Regione Lombardia. ERSAF e Agriteam (a c. di) in L'acqua, una risorsa per il sistema agricolo lombardo, 27-30, 2006 (in Italian).

Eijkelkamp, Guelph Permeameter Model 2800K1: operating instructions, 44 pp., 2011 Edn., http://en. eijkelkamp.com/products/field-measurement-equipment/ guelph-constant-head-permeameter.html (last access: September 2014), 2011.
English, M. J., Solomon, K. H., and Hoffman, G. J.: A paradigm shift in irrigation management, J. Irrig. Drain. Eng.-ASCE, 128, 267-277, 2002.

Farré, I. and Faci, J. M.: Deficit irrigation in maize for reducing agricultural water use in a Mediterranean environment, Agr. Water Manage., 96, 383-394, 2009.

Geerts, S. and Raes, D.: Deficit irrigation as an on-farm strategy to maximize crop water productivity in dry areas, Agr Water Manage., 96, 1275-1284, 2009.

Gowing, J. W. and Ejieji, C. J.: Real-time scheduling of supplemental irrigation for potatoes using a decision model and short term weather forecasts, Agr. Water Manage., 47, 137-153, 2001.

Hargreaves, G. H. and Samani Z. A.: Reference crop evapotranspiration from temperature, Appl. Eng. Agr., 1, 96-99, 1985.

Hassanli, A. M., Ebrahimizadeh, M. A., and Beecham, S.: The effects of irrigation methods with effluent and irrigation scheduling on water use efficiency and corn yields in an and region, Agr. Water Manage., 96, 93-99, 2009.

IPCC, 2013: Summary for Policymakers, in: Climate Change 2013: The Physical Science Basis. Contribution of Working Group I to the Fifth Assessment Report of the Intergovernmental Panel on Climate Change, edited by: Stocker, T. F., Qin, D., Plattner, G.K., Tignor, M., Allen, S. K., Boschung, J., Nauels, A., Xia, Y., Bex, V. and Midgley, P. M., Cambridge University Press, Cambridge, United Kingdom and New York, NY, USA.

Jensen, A. L. and Thysen, I.: Agricultural information and decision support by sms, EFITA Conference, 2003.

Jolliffe, I. T. and Stephenson, D. B.: Forecast Verification: A Practitioner's Guide in Atmospheric Science, John Wiley and Sons, Chichester, England, 2003.

Kuo, S. F. and Liu, C. W.: Simulation and optimization model for irrigation planning and management, Hydrol. Process., 17, 31413159, 2003.

Maidment, D. R.: Handbook of Hydrology, McGraw-Hill, New York, p. 5.14, 1993.

Masseroni, D., Ravazzani, G., Corbari, C., and Mancini, M.: Turbulence integral length and footprint dimension with reference to experimental data measured over maize cultivation in Po Valley, Italy, Atmosfera, 25, 183-198, 2012.

Maugeri, M. Variabilità e cambiamenti climatici nel corso degli ultimi due secoli: evidenze osservative e problemi aperti. ERSAF e Agriteam (a c. di) in L'acqua, una risorsa per il sistema agricolo lombardo, 17-23, 2006 (in Italian).

Montaldo, N., Ravazzani, G., and Mancini, M.: On the prediction of the Toce alpine basin floods with distributed hydrologic models, Hydrol. Process., 21, 608-621, 2007.

Montaldo, N., Toninelli, V., Albertson, J. D., Mancini, M., and Troch, P. A.: The effect of background hydrometeorological conditions on the sensitivity of evapotranspiration to model parameters: analysis with measurements from an Italian alpine catchment, Hydrol. Earth Syst. Sci., 7, 848-861, doi:10.5194/hess-7848-2003, 2003.

Monteith, J. L.: Evaporation and environment. Proc., Symposium of the Society for Experimental Biology: The State and Movement of Water in Living Organisms, Academic Press, Inc., NY., 19, 205-234, 1965.

Nagesh Kumar, D., Srinivasa Raju, K., and Ashok, B.: Optimal reservoir operation for irrigation of multiple crops using genetic algorithms, J. Irrig. Drain. Eng., ASCE 132, 123-129, 2006. 
Nash, J. E. and Sutcliffe, J. V.: River flow forecasting through the conceptual models, Part 1: A discussion of principles, J. Hydrol., 10, 282-290, 1970.

Oweis, T. and Hachum, A.: Optimizing supplemental irrigation: tradeoffs between profitability and sustainability, Agr. Water Manage., 96, 511-516, 2009.

Rabuffetti, D., Ravazzani, G., Corbari, C., and Mancini, M.: Verification of operational Quantitative Discharge Forecast (QDF) for a regional warning system - the AMPHORE case studies in the upper Po River, Nat. Hazards Earth Syst. Sci., 8, 161-173, doi:10.5194/nhess-8-161-2008, 2008.

Ravazzani, G: MOSAICO, a library for raster based hydrological applications, Comput. Geosci., 51, 1-6, 2013.

Ravazzani, G., Corbari, C., Morella, S., Gianoli, P., and Mancini, M.: Modified Hargreaves-Samani equation for the assessment of reference evapotranspiration in Alpine river basins, J. Irrig. Drain. Eng., 138, 592-599, 2012.

Ravazzani, G., Giudici, I., Schmidt, C., and Mancini, M.: Evaluating the potential of quarry lakes for supplemental irrigation, J. Irrig. Drain. Eng., 137, 564-571, 2011a.

Ravazzani, G., Mancini, M., Giudici, I., and Amadio, P.: Effects of soil moisture parameterization on a real- time flood forecasting system based on rainfall thresholds, in: Quantification and Reduction of Predictive Uncertainty for Sustainable Water Resources Management, Proc. Symposium HS 2004 at IUGG 2007, Perugia, July 2007, IAHS Publ., 313, 407-416, 2007.
Ravazzani, G., Rametta, D., and Mancini, M.: Macroscopic Cellular Automata for groundwater modelling: a first approach, Environ. Modell. Softw., 26, 634-643, 2011b.

Salerno, R., Giuliacci, M., and Bertolani, L.: Climate Change in Italy: An assessment of data and reanalysis models, Elsevier, Develop. Earth Surf. Process., 10, 123-132, 2007.

Skamarock, W. C. and Klemp, J. B.: A time-split non hydrostatic atmospheric model for research and NWP applications, J. Comput. Phys., 227, 3465-3485, 2008.

Smith, M.: CROPWAT - A computer program for irrigation planning and management, FAO Irrig. Drain. paper 46, Rome, FAO, 1992.

Vico, G., and Porporato, A.: Probabilistic description of crop development and irrigation water requirements with stochastic rainfall, Water Resour. Res., 49, 1466-1482, 2013.

Vico, G. and Porporato, A. From rainfed agriculture to stressavoidance irrigation: I. A generalized irrigation scheme with stochastic soil moisture, Adv. Water Resour., 34, 263-271, 2011.

Wilks, D. S.: Statistical Methods in the Atmospheric Sciences", Academic Press, Elsevier, 2nd Edn., 2006.

Zappa, M., Rotach, M. W., Arpagaus, M., Dorninger, M., Hegg, C., Montani, A., Ranzi, R., Ament, F., Germann, U., Grossi, G., Jaun, S., Rossa, A., Vogt, S., Walser, A., Wehrhan, J., and Wunram, C.: MAP D-PHASE: Real-time demonstration of hydrological ensemble prediction systems, Atmos. Sci. Lett., 2, 80-87, 2008. 